\title{
Does Cannabis Composition Matter? Differential Effects of Delta-9-tetrahydrocannabinol and Cannabidiol on Human Cognition
}

\author{
Marco Colizzi $^{1} \cdot$ Sagnik Bhattacharyya $^{1}$
}

Published online: 29 April 2017

(C) The Author(s) 2017. This article is an open access publication

\begin{abstract}
Purpose of Review The lack of clarity about the effect of cannabis use on cognition may be attributable to the considerable heterogeneity among studies in terms of cannabis composition. This article selectively reviews studies examining the distinctive effects of cannabinoids on human cognition, particularly those of delta-9-tetrahydrocannabinol $(\Delta 9-\mathrm{THC})$ and cannabidiol (CBD).

Recent Findings Research indicates that $\triangle 9$-THC administration acutely impairs cognition, particularly memory and emotional processing. Limited evidence suggests that CBD administration might improve cognition in cannabis users but not in individuals with neuropsychiatric disorders. Moreover, studies indicate that some acute $\triangle 9$-THC-induced cognitive impairments may be prevented if $\Delta 9$-THC is administered in combination or following CBD treatment. $\Delta 9$ THC and CBD have also shown opposite effects on cognitionrelated brain activation, possibly reflecting their antagonistic behavioral effects.

Summary Research suggests greater cognitive impairments in individuals when exposed to high $\triangle 9$-THC or low CBD cannabis. It is unclear whether at specific concentrations CBD might outweigh any harmful effects of $\Delta 9$-THC on cognition.
\end{abstract}

Keywords Cannabis · Delta-9-tetrahydrocannabinol · Cannabidiol $\cdot$ Cognitive processing $\cdot$ Brain function

This article is part of the Topical Collection on Cannabis

Sagnik Bhattacharyya

sagnik.2.bhattacharyya@kcl.ac.uk

1 Department of Psychosis Studies, Institute of Psychiatry, Psychology and Neuroscience, King's College London, London SE5 8AF, UK

\section{Introduction}

Interest in the effects of cannabis on human cognition stems from evidence regarding its role as the most widely used illicit drug [1] as well as an important risk factor for the development of psychosis [2,3] and its relapse [4-8], the latter being also consistent with evidence that delta-9tetrahydrocannabinol $(\triangle 9-\mathrm{THC})$, the main psychoactive ingredient of the Cannabis sativa plant, can induce transient psychotic symptoms upon acute administration in healthy volunteers [9-11]. This body of research is also consistent with independent evidence of endocannabinoid system abnormalities in psychosis [12], a disorder characterized by abnormalities in different cognitive processes [13].

However, evidence regarding the association between cannabis use and impairments in cognitive processing is less clear. While one may intuitively expect cannabis to have a deleterious effect on cognitive performance, studies in healthy volunteers have reported some discrepancies. For example, some studies suggest that healthy cannabis users show poorer cognitive performance [14-17]. Others report no difference in cognitive processing as a function of cannabis use [18]. Even more conflicting results are present in studies in patients with schizophrenia. While some studies suggest poorer cognitive functions in patients with a history of cannabis exposure [19], others indicate better performance $[15,20]$ or no change $[17$, $21]$ in cannabis-using patients.

Variation in the results of studies investigating the effect of cannabis use on cognitive functioning, as outlined above, might have several explanations. These discrepancies may be because of genetic variation having an impact on cognitive phenotypes [22-29]. Moreover, it may reflect selective effect on certain aspects of cognition as suggested by available evidence, with a robust but modest deleterious impact on global memory function, a more pronounced detrimental effect on 
specific memory sub-domains such as prospective and retrospective verbal and visual memory, and limited effect on other cognitive domains $[17,30]$. It may also reflect variation between different studies in the duration of cannabis exposure and/or of abstinence at the time of cognitive testing of study participants, as available evidence points towards a dosedependent effect with cognitive impairment being more marked following persistent cannabis use and incomplete restoration of function following cessation of use [31]. Evidence from imaging studies also suggests that both chronic [32, 33] and acute cannabis exposure [34] might disrupt activity in brain networks involved in cognitive processing without necessarily affecting behavioral performance, suggesting either a deployment of greater neural effort or a change in strategy to maintain adequate task performance [35], thereby accounting for different effects in different individuals.

Independent of these potential explanations, the lack of a clear association between cannabis use and impairments in cognition may also to a large extent be attributable to the considerable heterogeneity in recreational cannabis that participants in these studies may have been exposed to, as well as the differing effects on cognition of the various chemicals found in the extract of the cannabis plant. The extract of Cannabis sativa has over 60 different cannabinoids [36], with $\triangle 9$-THC and cannabidiol (CBD) being the most prominent among them. However, while $\triangle 9$-THC is thought to be responsible for most of its psychotropic effects [37], CBD is under investigation for its potential antipsychotic effects, in opposition to the propsychotic effects of $\triangle 9$-THC. Research also suggests that CBD can counteract the negative effects of $\Delta 9-\mathrm{THC}$, as investigated in both humans and animal models at a behavioral and neurochemical level [38-41]. This is of crucial importance considering that case-control studies suggest that the risk of development and relapse of psychosis in cannabis users depends on both frequency of use and cannabis potency [5, 42], with the risk being the highest in individuals exposed on a daily basis to cannabis with a high $\triangle 9$-THC concentration, and unchanged among users of cannabis with a lower $\Delta 9$-THC concentration and a more balanced $\triangle 9$-THC:CBD ratio. In line with evidence from human studies, research investigating the effect of different cannabinoids in animal models has consistently reported behavioral abnormalities following $\triangle 9$-THC exposure. $\triangle 9$-THC exposure during adolescence has been associated with long-term behavioral alterations in adult rats, such as recognition memory deficits, social withdrawal, and altered emotional reactivity [43]. Other evidence suggests enduring cognitive impairment in the offspring of rats exposed to $\triangle 9$-THC during the perinatal period [44]. Interestingly, altered behavior and cognition in animal models may be directly related to the $\Delta 9$-THCinduced dysfunction of the glutamatergic and noradrenergic systems via cannabinoid receptor 1 activation, and this altered neurotransmission can be prevented or reversed if CBD is administered before or after $\Delta 9$ THC exposure, respectively [40, 43, 44].

Together, these findings underscore how the effects of different cannabinoids, which are often present in varying concentration in the cannabis available for use in the street, may confound the results of human studies investigating cognitive alterations associated with recreational cannabis use. In this article, we carry out a narrative review of studies examining the acute effects of cannabis on human cognition and related brain function, with emphasis on the distinctive effects of the different cannabinoids that have been examined to date, particularly $\triangle 9$-THC and CBD, in order to disentangle their contribution to specific cognitive processes.

\section{Methods}

In order to disentangle the effect of different cannabinoids on cognitive domains relevant to neuropsychiatric disorders, this literature review aimed to mainly focus on human studies that examined the impact of $\triangle 9$-THC in contrast with CBD and other cannabinoids on cognitive functioning using cannabis/ cannabinoid challenge paradigms. Functional magnetic resonance imaging (fMRI) studies examining the neural correlates of the effects of $\triangle 9$-THC and CBD on human cognition and the role of other cannabinoids in modulating cognitive processes during a cannabis/ $\triangle 9$-THC challenge are also discussed.

\section{Search Strategy}

A literature search was performed using electronic databases (MEDLINE, Web of Science, and Scopus) for original English-language research articles published over the last 25 years (1990-2016). Keywords included delta-9-tetrahydrocannabinol, cannabidiol, cognition, cognitive dysfunction/impairment, and memory/learning. Reference lists of eligible studies were also screened to identify additional studies.

\section{Eligibility Criteria}

Studies were eligible for inclusion in this review if they had assessed the effect of $\triangle 9$-THC and CBD or another cannabinoid on cognition during acute challenge investigations. Studies were excluded if they (i) did not assess the effects of $\triangle 9$-THC, CBD, or other cannabinoids on cognition in experimental studies; (ii) did not investigate the role of different cannabinoids on cognition; (iii) primarily assessed psychological or psychiatric parameters rather than cognition. 


\section{Results}

\section{Evidence at a Glance}

A number of studies have assessed the effect of $\triangle 9$-THC alone on cognition [41, 45-49]. However, only a limited body of research has specifically compared the effect of different cannabinoids on human cognition, which has also been reviewed before focusing primarily on neuroimaging studies $[41,49]$. These studies have used different experimental designs and studied heterogeneous populations. In particular, eight human studies were identified on the behavioral effects of $\triangle 9$-THC and CBD, which investigated (i) cognitive function in cannabis users using products with a high or low $\Delta 9$ THC:CBD ratio, in both the intoxicated and unintoxicated state $[50,51]$; (ii) cognitive function in healthy subjects fol-

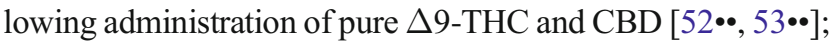
(iii) cognitive function in healthy subjects following administration of standardized cannabis extracts with defined $\Delta 9$ THC:CBD ratios [54, 55]; (iv) cognitive function in human subjects prescribed with medical marijuana (MMJ) containing a low/balanced $\Delta 9$-THC:CBD ratio [56, 57].

Similarly, a review carried out in 2014 identified 24 studies which used fMRI paradigms to explore the acute effects of $\triangle 9$-THC or CBD on human brain function [49]. Most of these studies have investigated how these cannabinoids modulate brain activity in the resting state or during cognitive processing. However, a limited number of studies have specifically compared the effects of pure $\triangle 9$-THC and CBD on the neural substrates of human cognition $[58 \bullet \bullet, 59,60,61 \bullet \bullet]$.

Finally, only one study has investigated the effect of another cannabinoid, delta-9-tetrahydrocannabivarin $(\triangle 9-\mathrm{THCV})$, by comparing its effects on cognition with that of pure $\Delta 9$ THC in healthy subjects [62] (Tables 1 and 2).

In contrast to studies on the effects of cannabis or $\Delta 9$-THC on cognition, there has been very limited examination on the effect of CBD alone on human cognition, with only two studies assessing the effect of CBD on cognitive function in healthy subjects [58••] and in schizophrenia patients [63], respectively. One of those exposed healthy participants to $\Delta 9$ -

Table 1 Studies included in the review

\begin{tabular}{|c|c|c|c|c|}
\hline Study & Type of study & Study sample & $\begin{array}{l}\text { Cannabinoids } \\
\text { investigated }\end{array}$ & Cognitive domain investigated \\
\hline $\begin{array}{l}\text { Wade et al. } 2003 \\
\text { [57] }\end{array}$ & $\begin{array}{l}\text { Randomized, double-blind, } \\
\text { cross-over, behavioral study }\end{array}$ & $\begin{array}{l}\text { Patients with } \\
\text { neurological } \\
\text { disorders }\end{array}$ & $\begin{array}{l}\Delta 9-\mathrm{THC}, \\
\Delta 9-\mathrm{THC}+ \\
\mathrm{CBD}, \mathrm{CBD}\end{array}$ & Attention \\
\hline $\begin{array}{l}\text { Roser et al. } 2008 \\
\quad[54]\end{array}$ & $\begin{array}{l}\text { Double-blind, cross-over, EEG } \\
\text { study }\end{array}$ & Healthy participants & $\begin{array}{l}\Delta 9-\mathrm{THC} \\
\quad \Delta 9-\mathrm{THC}+\mathrm{CBD}\end{array}$ & Attention, processing speed \\
\hline $\begin{array}{l}\text { Morgan et al. } 2010 \\
{[51]}\end{array}$ & Naturalistic, behavioral study & Cannabis users & $\Delta 9-\mathrm{THC}+\mathrm{CBD}$ & Verbal memory, episodic memory, executive function \\
\hline $\begin{array}{l}\text { Bhattacharyya } \\
\text { et al. } 2010 \\
{[58 \cdot \bullet]}\end{array}$ & $\begin{array}{l}\text { Randomized, double-blind, } \\
\text { cross-over fMRI study }\end{array}$ & Healthy participants & $\triangle 9-\mathrm{THC}, \mathrm{CBD}$ & $\begin{array}{l}\text { Verbal memory, emotional processing, executive } \\
\text { function, visual and auditory processing }\end{array}$ \\
\hline $\begin{array}{l}\text { Schoedel et al. } \\
2011[55]\end{array}$ & $\begin{array}{l}\text { Randomized, double-blind, } \\
\text { cross-over, behavioral study }\end{array}$ & $\begin{array}{l}\text { Recreational cannabis } \\
\text { users }\end{array}$ & $\begin{array}{l}\Delta 9-\mathrm{THC} \\
\quad \Delta 9-\mathrm{THC}+\mathrm{CBD}\end{array}$ & Attention, processing speed, working memory \\
\hline $\begin{array}{l}\text { Winton-Brown } \\
\text { et al. } 2011 \text { [59] }\end{array}$ & $\begin{array}{l}\text { Pseudo-randomized, double-blind, } \\
\text { cross-over, fMRI study }\end{array}$ & Healthy participants & $\triangle 9-\mathrm{THC}, \mathrm{CBD}$ & Visual and auditory processing \\
\hline $\begin{array}{l}\text { Bhattacharyya } \\
\text { et al. } 2012[60]\end{array}$ & $\begin{array}{l}\text { Randomized, double-blind, } \\
\text { cross-over, fMRI study }\end{array}$ & Healthy participants & $\triangle 9$-THC, CBD & Attentional salience processing \\
\hline $\begin{array}{l}\text { Morgan et al. } 2012 \\
{[50]}\end{array}$ & Naturalistic, behavioral study & Cannabis users & $\Delta 9-\mathrm{THC}+\mathrm{CBD}$ & $\begin{array}{l}\text { Verbal memory, episodic memory, recognition } \\
\text { memory }\end{array}$ \\
\hline $\begin{array}{l}\text { Englund et al. } 2013 \\
{[52 \bullet \bullet]}\end{array}$ & $\begin{array}{l}\text { Randomized, double-blind, } \\
\text { behavioral study }\end{array}$ & Healthy participants & $\begin{array}{l}\Delta 9-\mathrm{THC} \\
\quad \Delta 9-\mathrm{THC}+\mathrm{CBD}\end{array}$ & Verbal memory, working memory, executive function \\
\hline $\begin{array}{c}\text { Bhattacharyya } \\
\text { et al. } 2015 \\
{[61 \bullet \bullet]}\end{array}$ & $\begin{array}{l}\text { Randomized, double-blind, } \\
\text { cross-over, fMRI study }\end{array}$ & Healthy participants & $\triangle 9-\mathrm{THC}, \mathrm{CBD}$ & Attentional salience processing \\
\hline $\begin{array}{l}\text { Hindocha et al. } \\
2015[53 \cdot \bullet]\end{array}$ & $\begin{array}{l}\text { Randomized, double-blind, } \\
\text { cross-over, behavioral study }\end{array}$ & Cannabis users & $\begin{array}{r}\Delta 9-\mathrm{THC}, \\
\Delta 9-\mathrm{THC}+ \\
\mathrm{CBD}, \mathrm{CBD}\end{array}$ & Emotional processing \\
\hline $\begin{array}{l}\text { Gruber et al. } 2016 \\
\text { [56] }\end{array}$ & Longitudinal, behavioral study & $\begin{array}{r}\text { Patients certified for } \\
\text { medical cannabis }\end{array}$ & $\Delta 9-\mathrm{THC}+\mathrm{CBD}$ & Executive function, processing speed \\
\hline $\begin{array}{l}\text { Englund et al. } 2016 \\
\text { [62] }\end{array}$ & $\begin{array}{l}\text { Double-blind, cross-over, } \\
\text { behavioral study }\end{array}$ & Healthy participants & $\begin{array}{l}\Delta 9-\mathrm{THC}, \\
\Delta 9-\mathrm{THC}+ \\
\Delta 9-\mathrm{THCV}\end{array}$ & Verbal memory, working memory \\
\hline
\end{tabular}

$E E G$ electroencephalography, $f M R I$ functional magnetic resonance imaging, $\triangle 9$-THC delta-9-tetrahydrocannabinol, $C B D$ cannabidiol, $\triangle 9-T H C V$ delta9 -tetrahydrocannabivarin, + investigated in combination 


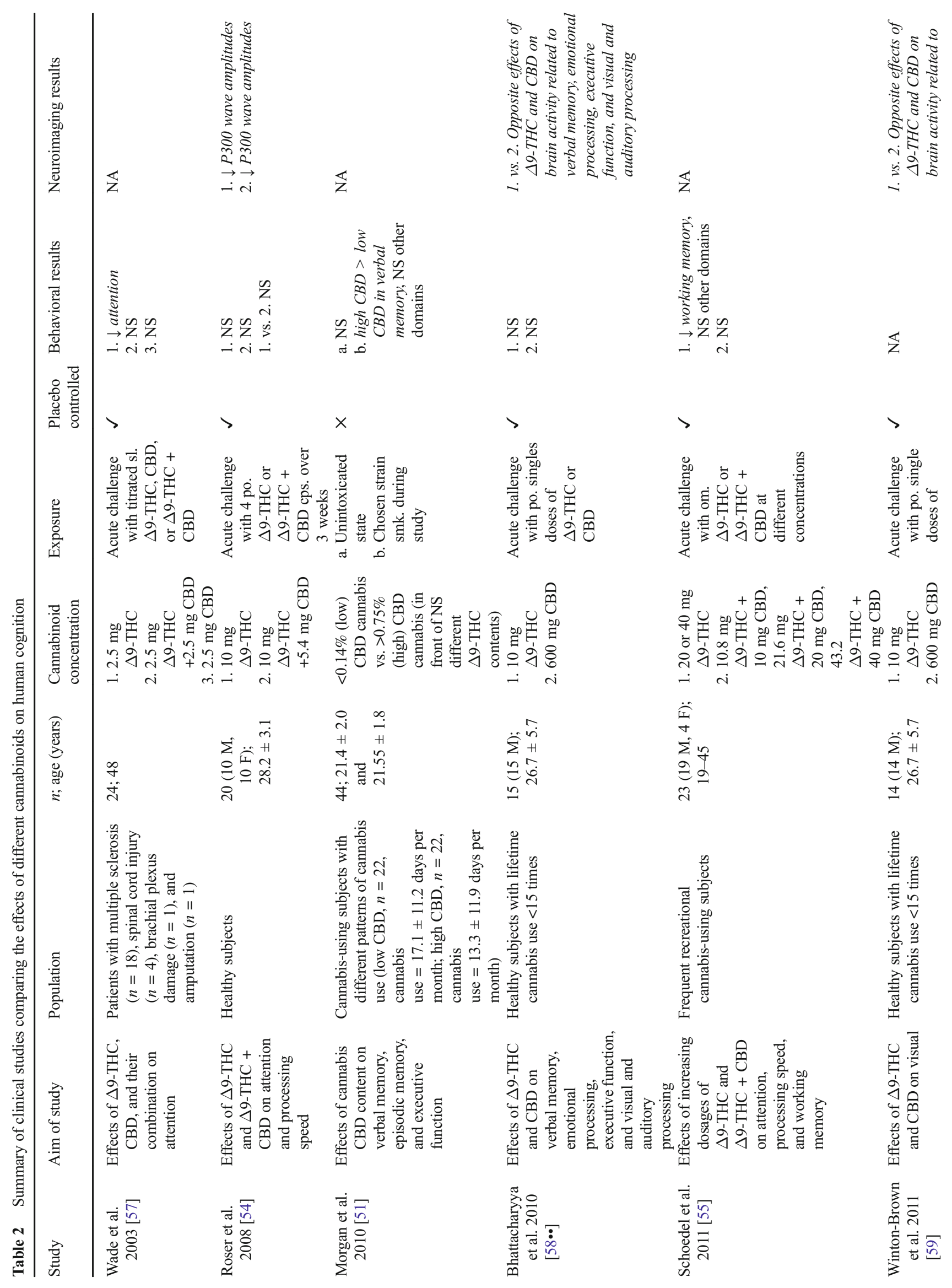




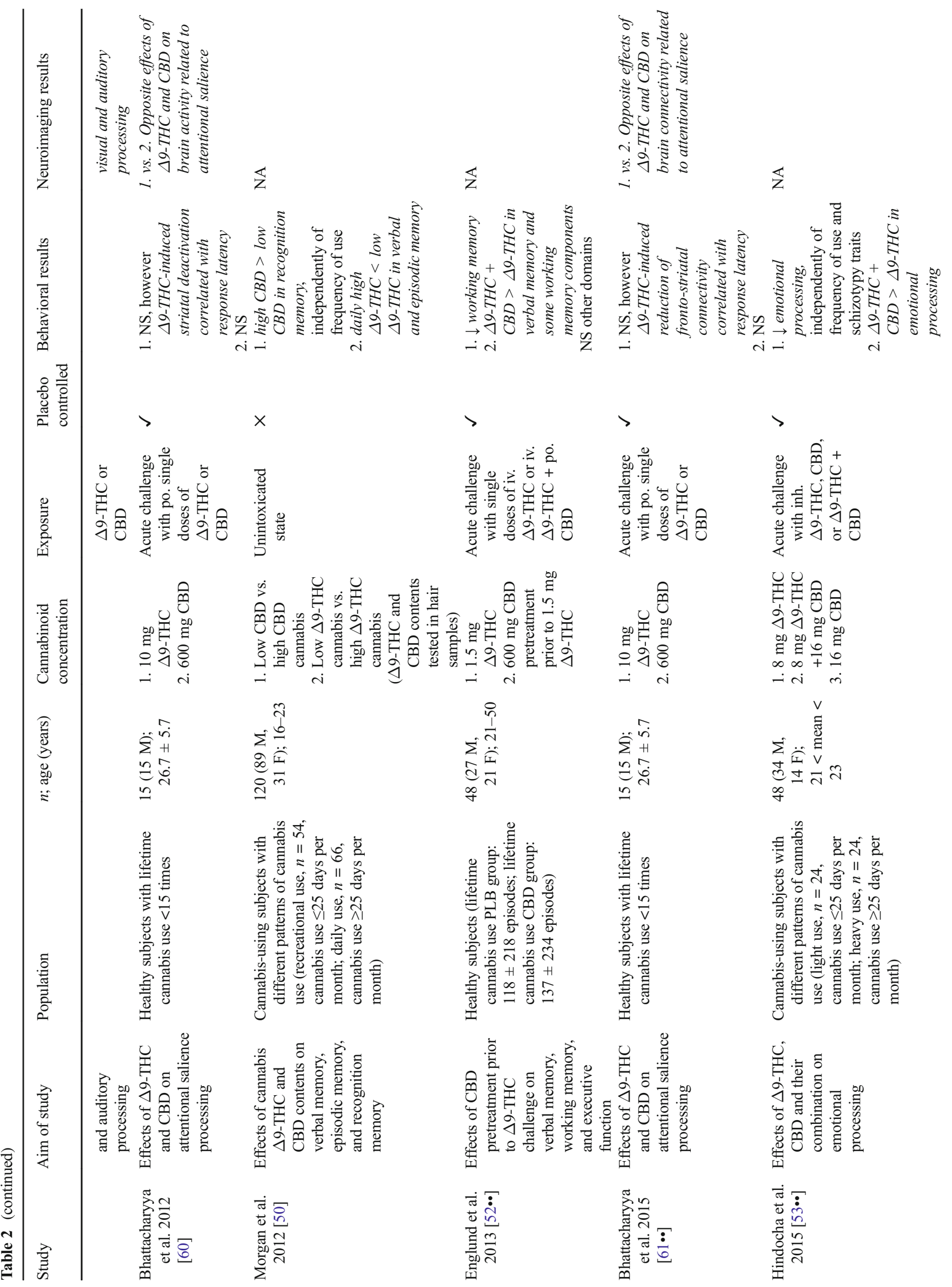




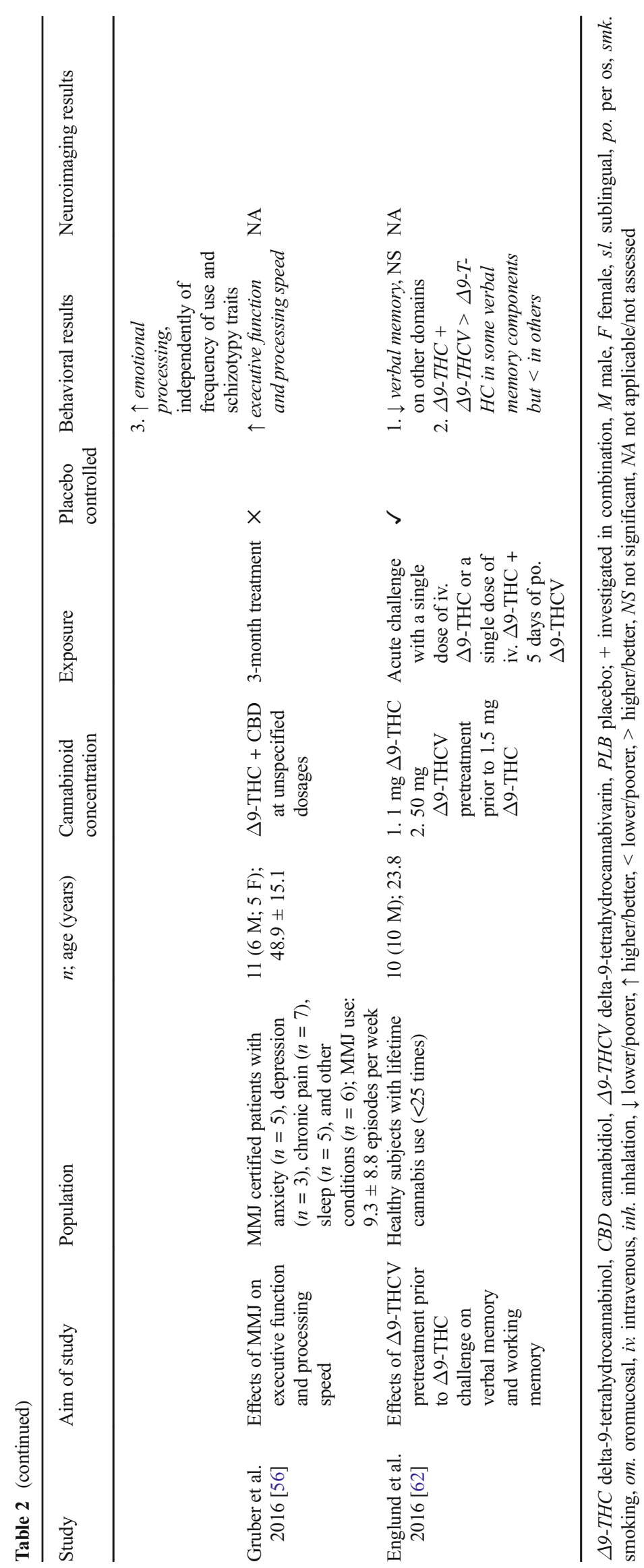


THC, CBD, or placebo on separate occasions and is therefore included in this review [58••]. The other study represents the only published clinical trial to investigate the therapeutic potential of CBD to treat cognitive impairment in a neuropsychiatric condition. Unfortunately, it failed to show a significant cognitive improvement in schizophrenia patients treated with CBD [63].

\section{Cognitive Function in Cannabis Users Using Products with a High or Low $\Delta 9$-THC:CBD Ratio}

The relative ratio of $\Delta 9$-THC and CBD varies greatly in cannabis available on the street. For instance, in the UK, more recent varieties of cannabis, such as "skunk," have been shown to contain more $\triangle 9$-THC and virtually no CBD compared to the traditional "hash" variety [64]. A shift towards use of high-potency cannabis with higher levels of $\Delta 9$-THC and lower levels of CBD has been reported also in the USA [65] and Australia [66]. In 2012, a meta-analysis of the studies published over the previous three decades indicated that there has been a consistent increase in cannabis potency worldwide [67]. Recent research has indicated that the use of skunk-like high-potency cannabis might have a more detrimental effect on mental health than the use of the traditional low-potency cannabis [5, 42], suggesting that the harmful effect of cannabis might be driven by the high $\triangle 9-\mathrm{THC} /$ low CBD contained in the used strain. However, despite being consistent so far, evidence is too limited to draw definitive conclusions.

In a naturalistic study [51], Morgan and colleagues investigated cognitive processing among cannabis users as a function of the CBD content in the cannabis strain used by the study participants. Results indicate that, upon acute intoxication, participants using low-CBD cannabis $(<0.14 \% ; n=22)$ performed worse than those using high-CBD cannabis $(>0.75 \% ; n=22)$ on a verbal memory task, despite there being no difference in the concentration of $\Delta 9$-THC present in the cannabis used during the experiment or in the baseline (before acute intoxication) verbal memory performance between the low- and high-CBD cannabis-using groups. Moreover, this effect was still significant when controlling for the confounding effect of alcohol use and intelligence. Together, these results suggest that CBD may attenuate the acute memoryimpairing effects of $\Delta 9$-THC.

In a second experiment, Morgan and colleagues assessed cognitive functioning in chronic cannabis users when they were not intoxicated as a function of the $\triangle 9$-THC:CBD ratio in the strain of cannabis they used [50]. Results revealed a better recognition memory in subjects using high-CBD cannabis compared to that in subjects using low-CBD cannabis. Also, this association was independent of the frequency of use (recreational use, $n=54$; daily use, $n=66$ ). Further analysis also suggested an association between daily use of high $\Delta 9$ THC cannabis and disruption of verbal and episodic memory.
Altogether, evidence from these studies suggests a higher risk of memory disruption associated with consuming cannabis strains with high $\Delta 9-\mathrm{THC}$ and low $\mathrm{CBD}$ content.

\section{Cognitive Function in Healthy Subjects Following Administration of Pure $\Delta$ 9-THC and CBD}

A number of studies have investigated the effects of the major cannabinoids such as $\triangle 9$-THC and CBD administered as pure pharmacological grade substance to avoid the confounding effects of different $\mathrm{CBD}$ and $\triangle 9$-THC concentrations and other cannabinoids present in the cannabis extract. This research design, which has been successfully used in preclinical models, represents a promising paradigm in understanding the neurobiological mechanisms underlying the effects of cannabinoids on cognition [40].

Hindocha and colleagues investigated the main effects and interaction of $\triangle 9$-THC and CBD on facial emotion recognition [53••]. Cannabis-using participants $(n=48)$ received $\Delta 9$ THC, CBD, or their combination $(\triangle 9-\mathrm{THC}+\mathrm{CBD})$ over separate sessions. Results indicate a detrimental effect of administration of $\triangle 9$-THC alone on emotional processing accuracy, which was no longer present when participants received the $\triangle 9-\mathrm{THC}+\mathrm{CBD}$ combination. Furthermore, administration of CBD alone was associated with higher emotional processing accuracy compared to placebo. This study also revealed that the effects of $\triangle 9$-THC and CBD on emotional processing were not affected by the participants' frequency of cannabis use or schizotypal traits.

Using a slightly different approach, another study investigated the putative protective effect of CBD against $\Delta$ 9-THCinduced impairments in cognitive processing [52••]. Healthy participants were randomized to receive CBD or placebo before being intravenously administered with $\triangle 9$-THC. Compared to the CBD pretreatment group $(n=22)$, the placebo pretreatment group $(n=26)$ showed a poorer verbal memory performance following $\triangle 9$-THC administration. Moreover, while $\Delta 9$-THC affected working memory performance in participants pretreated with placebo, pretreatment with CBD was able to partially prevent the detrimental effects of $\triangle 9$-THC on this cognitive domain.

\section{Cognitive Function in Healthy Subjects Following Administration of Standardized Cannabis Extracts with Defined $\Delta$ 9-THC:CBD Ratios}

A few studies have investigated the effect of standardized cannabis extracts containing precise combinations of $\Delta 9$ THC and CBD. This approach complements studies investigating the effects of pure pharmacological grade cannabinoids by shedding new light on the potential cognitive mechanisms that may underpin the harmful effects of specific types of recreational cannabis $[5,42]$. 
Roser and colleagues investigated whether the acute effect of standardized cannabis extracts on selective attention varies as a function of $\triangle 9$-THC being administered alone or in combination with CBD [54]. Results indicate that cognitive performance among healthy participants $(n=20)$ did not differ significantly when administered with $\triangle 9$-THC alone or in combination with CBD. However, compared to placebo, both $\triangle 9$-THC alone and combined $\Delta$ 9-THC and CBD administration affected the attention-related electrophysiological response. Another study assessed attention and working memory, exposing recreational cannabis users to increasing dosages of $\triangle 9$-THC alone or to cannabis extracts containing increasing balanced dosages of both $\Delta 9$-THC and CBD [55]. Results suggest that higher doses of $\triangle 9-\mathrm{THC}$ were associated with longer latency for short-term memory. Interestingly, this effect on working memory was no longer present when participants received any of the cannabis extracts containing both $\triangle 9$-THC and CBD.

\section{Cognitive Function in Individuals Treated with Medical Marijuana}

So far, only two studies have investigated the effect of MMJ on cognition. Wade and colleagues tested for the effect of $\Delta 9$ THC, CBD, and a MMJ product containing a 1:1 $\Delta 9$ THC:CBD ratio in patients with different neurological disorders, mainly multiple sclerosis $(n=24)$ [57]. Administration of $\triangle 9$-THC alone affected cognition in patients, as assessed with a Short Orientation Memory Concentration test. Despite no main effect of CBD on its own, when administered in combination with $\triangle 9-\mathrm{THC}$ in the MMJ product, it prevented the $\Delta$ 9-THC-induced detrimental effect on cognition. More recently, a pilot study has assessed the potential effect of a 3month treatment with MMJ on executive function [56]. Despite the modest sample size $(n=11)$, patients certified for MMJ use experienced some improvement on measures of executive function, mostly reflecting an increased processing speed with preserved task accuracy.

\section{Neural Substrates of Human Cognition Modulated by Administration of Pure $\Delta \mathbf{9}$-THC and CBD}

Over the years, imaging studies investigating how cannabinoids modulate human brain function have employed progressively more sophisticated designs. Recent studies have allowed investigation of the effect of acute cannabinoid administration on neural networks underlying specific cognitive domains and their relationship to any concomitant effect on cognitive task performance and neuropsychiatric symptomatology induced by the cannabinoids. This body of research has complemented the behavioral evidence, testing specific hypotheses for a role of the endocannabinoid system in various cognitive processes.
Bhattacharyya and colleagues directly contrasted for the first time the effects of $\triangle 9$-THC and CBD administration on brain function and related behavior $(n=15)$ in healthy individuals, reporting opposite effects relative to placebo across different cognitive domains [58••]. More specifically, during the retrieval condition of a verbal memory task, CBD acutely increased activation of the striatum and prefrontal cortex relative to the placebo condition. Conversely, $\Delta 9$-THC reduced activity in these regions and the reduced striatal activation correlated with the severity of the psychotic symptoms induced by it. Both $\triangle 9$-THC and CBD modulated the activation of the amygdala and related brain regions involved in fear processing, which correlated with their opposing effects on anxiety, with effects of $\Delta 9$-THC correlating with increase in anxiety symptoms and fear-related autonomic arousal induced by it and effects of CBD correlating with a reduction in anxiety and attenuation of fear-related autonomic arousal under its influence. During a response inhibition task, activation in the parahippocampal gyrus bilaterally and in the left insula and caudate was attenuated following $\triangle 9-\mathrm{THC}$ administration, but enhanced under CBD. Finally, $\triangle 9-$ THC and CBD induced opposite effects while processing a response inhibition task and auditory and visual stimuli.

In another study from the same sample, the authors reported opposite effects of $\triangle 9$-THC and CBD administration relative to that of placebo on several brain areas during attentional salience processing [60]. More specifically, $\triangle 9-\mathrm{THC}$ acutely reduced striatal activation which correlated with the severity of the $\Delta 9$-THC-induced psychotic symptoms as well as the $\Delta 9$-THC-induced behavioral response latency. A recent investigation in the same sample compared the effects of $\Delta 9$ THC and CBD administration on functional connectivity during the salience processing task $[61 \bullet \bullet]$. In line with previous reports, the two cannabinoids had opposite effects on functional connectivity between the dorsal striatum, the prefrontal cortex, and the hippocampus. Specifically, mediotemporalprefrontal connectivity was enhanced under the $\Delta 9$-THC condition but reduced following CBD administration. Instead, fronto-striatal connectivity was enhanced by $\mathrm{CBD}$ but reduced under $\Delta 9$-THC. The effect of $\Delta 9$-THC on fronto-striatal connectivity also correlated with response latency while performing the task.

Another study has directly compared the effects of $\Delta 9$ THC and CBD administration on the processing of auditory and visual stimuli [59]. Compared to $\mathrm{CBD}$, while processing auditory stimuli, $\Delta 9$-THC administration was associated with reduced activity in the right superior and middle temporal gyri. During the visual processing condition, $\triangle 9$-THC increased activity in the primary visual cortex (left lingual and middle occipital gyri) but attenuated it in occipital regions bilaterally compared to CBD. $\triangle 9$-THC and CBD also had opposite effects on cerebellar activity during visual processing. 


\section{Cognitive Function in Healthy Subjects Following Administration of Pure $\Delta$ 9-THC and $\triangle 9$-THCV}

To date, human studies have typically focused on $\Delta 9$-THC and CBD, and their effects on brain function have been extensively studied and well understood [41]. Only one recent study has investigated the effect of another cannabinoid, $\triangle 9$-THCV, a cannabinoid receptor 1 (CB1) neutral antagonist, on cognition in humans [62]. Englund and colleagues assessed the acute effects of intravenous $\triangle 9$-THC administration on cognition in healthy subjects $(n=10)$ following pretreatment with $\triangle 9$-THCV or placebo for 5 days. Upon acute $\Delta 9$-THC administration, participants pretreated with placebo experienced an impairment in delayed verbal memory recall, which was no longer present when participants were investigated following pretreatment with $\Delta 9-\mathrm{THCV}$. However, compared to the placebo pretreatment condition, $\triangle 9$-THC administration following $\triangle 9$-THCV pretreatment was associated with significantly increased memory intrusions.

\section{Discussion}

\section{A Promising Approach to Understanding the Effects of Cannabinoids on Cognition}

Several potential confounders limit any inference being drawn from studies investigating the association between chronic or occasional cannabis exposure and cognitive processing alterations. These include (i) considerable variation in the ratio of different cannabinoids, in particular $\triangle 9$-THC:CBD ratio, in cannabis used recreationally; (ii) interindividual variation in frequency, quantity, and duration of cannabis use; (iii) modality of cannabis use, frequently consumed in combination with tobacco and/or other substances; and (iv) neuroadaptive changes that occur in relation to tolerance, withdrawal and/ or sensitization, and substance abuse/dependence in general. In an attempt to control for these factors, several studies have investigated the effect of each of these cannabinoids separately and contrasted them directly to determine whether the composition of cannabis matters in terms of its effects on human cognition. These pharmacological challenge studies, which we have reviewed here, offer the unique possibility of perturbing the endocannabinoid system under controlled experimental conditions and investigating their effect on various cognitive processes as well as acutely model cannabis-related neuropsychiatric manifestations. This line of research also allows us to systematically investigate under controlled experimental conditions the therapeutic potential or indeed the harmful effects of different cannabinoids that are increasingly being considered as treatment for various neurodegenerative and neuropsychiatric disorders. This research approach, especially when combined with neuroimaging techniques, can provide insight into the neurobiological mechanisms underlying the effects of cannabis on human cognition [11].

\section{Cannabis Composition and Altered Cognitive Processing: What and Where is the Evidence}

Most of the available evidence so far relates to pharmacological challenge studies involving two cannabinoids, $\triangle 9$-THC and CBD, the most known and investigated cannabinoids at a neurobiological level and in preclinical models [40]. Using different research strategies, these two cannabinoids have been administered as a crude extract (pure form), or in different concentrations within recreational cannabis, standardized cannabis extracts, or medicinal cannabis preparations.

\section{Effect of $\triangle 9$-THC on Human Cognition and Related Neural Activity}

Compared to studies assessing the long-lasting effects of cannabis use on cognition $[16,18,46,68-70]$, there is much better agreement across systematic experimental studies that $\Delta 9$-THC administration acutely impairs several cognitive domains, including emotional processing [53••], and verbal $[52 \bullet, 62]$ and working memory performance $[52 \bullet \bullet]$. Moreover, imaging studies have extended this evidence, indicating acute $\triangle 9$-THC-induced changes in the neural activity of brain areas underlying verbal memory, emotional and attentive processing, and processing of visual and auditory stimuli $[58 \bullet, 59,60,61 \bullet \cdot$. Intriguingly, under the acute effect of $\Delta 9$ THC, changes in these neural networks were associated with the acute manifestation of psychotic symptoms [58・・, 59, 60], anxiety [58••], and impaired cognition at a behavioral level $[61 \bullet \bullet]$.

\section{Effect of CBD on Human Cognition and Related Neural Activity}

Over the last few years, studies have also investigated the effect of acute CBD administration on cognition, in quest of a potential therapeutic effect of this cannabinoid [58・•]. This has followed evidence that CBD may be an antagonist/inverse agonist at cannabinoid receptor type 1 (CB1), in opposition to $\triangle 9$-THC partial agonist effect [71], and additional evidence for a potential anxiolytic effect of CBD, based on preclinical [72-76] and clinical [77, 78] studies. Limited evidence so far suggests that CBD administration might improve emotional processing accuracy in cannabis users [53••]. Evidence from imaging studies suggests that CBD attenuates amygdala activity while processing fearful stimuli, which was associated with an attenuation of anxiety and the normal autonomic arousal associated with fear processing [58••], consistent with independent evidence of its anxiolytic potential [79]. On the contrary, CBD administration did not improve cognitive 
functioning in individuals suffering from neurological disorders [57]. However, most of this evidence is based on single studies, which need independent replication.

\section{Comparison of the Effect of $\triangle 9$-THC and CBD on Human Cognition and Related Neural Activity}

Studies have investigated the effects of both $\triangle 9$-THC and $\mathrm{CBD}$, in their pure forms or in different combinations, in order to test whether CBD may protect from or reverse the adverse effects of $\triangle 9$-THC on cognition. Evidence from the studies reviewed here seems to suggest the following: (i) Acute cannabis-induced detrimental effects on verbal memory may be greater when exposed to low-CBD cannabis [51]; (ii) Chronic cannabis use may be associated with poorer verbal and episodic memory when exposed to low $\mathrm{CBD} /$ high $\Delta 9$ THC cannabis [50]; (iii) Acute $\Delta 9$-THC-induced detrimental effects on emotional processing and working memory are absent if $\triangle 9$-THC is administered in combination with CBD [53••, 55]; (iv) Acute effects of $\Delta 9-\mathrm{THC}$ on attention may not be distinguishable from acute effects of $\Delta 9$-THC administered in combination with CBD [54]; (v) Pretreatment with CBD may prevent the acute $\triangle 9$-THC-induced impairments in verbal and working memory processing [52••]; (vi) Acute $\Delta 9$ THC-induced impairments in cognition in patients with neurological disorders may be absent if $\Delta 9-\mathrm{THC}$ is administered in combination with CBD in medicinal cannabis preparation [57]; (vii) Medicinal cannabis, containing both $\triangle 9-$ THC and CBD, may have a beneficial effect on certain cognitive processes in patients certified for its use [56]; (viii) $\Delta 9$-THC and CBD have opposite effects on neural activity in brain areas related to several cognitive processes [58••, 59, 60, 61••]; (ix) Pretreatment with $\triangle 9$-THCV may prevent some of the acute $\triangle 9$-THC-induced detrimental effects on verbal memory. However, it is worth highlighting the need for independent replication of evidence summarized here before they may be generalized and useful for application in clinical settings.

\section{Limitations and Future Perspectives}

Studies included in this review need to be considered in light of some limitations. On the basis of current evidence, it is perhaps premature to conclude that any protective cognitive effects in naturalistic studies are wholly attributable to CBD, considering the numerous other chemicals present in cannabis $[50,51]$. It is unclear from existing research whether there is a specific ratio of $\triangle 9-\mathrm{THC}$ and $\mathrm{CBD}$ at which the beneficial effects of CBD outweigh any harmful effects of $\triangle 9$-THC on cognition, such that this ratio may serve as a threshold for consideration in the formulation of medicinal cannabis preparations [56]. Whether $\Delta 9-\mathrm{THCV}$ has any beneficial effect is unclear at this stage due to its mixed effects on memory and also because current evidence comes from a single human study with a modest sample size [62]. Research in humans, especially on the effect of CBD and other cannabinoids, is still in its infancy. So far, the only published study on the acute effect of CBD in schizophrenia has not shown any significant cognitive improvement [63]. Promising results of beneficial effects of CBD on cognition in the context of neuropsychiatric diseases come from preclinical studies on Alzheimer's disease $(\mathrm{AD})$, indicating improved recognition, social recognition, and spatial memory in AD paradigms following acute and chronic CBD treatment (reviewed in [80]). To our knowledge, no studies have explored the effect of CBD on cognition in other drug-induced states. Future investigations need to investigate the effect of different cannabinoids on human cognition to better understand their therapeutic potential as well as relevance for neuropsychiatric conditions where the endocannabinoid system or cannabis exposure may play a role $[12,41,42,81-84]$.

\section{Conclusions}

Available evidence suggests that acute $\Delta 9$-THC administration has an adverse effect on several cognitive domains. In particular, memory components appear to be the cognitive domains more consistently disrupted following acute $\Delta 9$ THC administration, including verbal, episodic, and working memory. Less strong evidence suggests a deleterious effect of $\Delta 9$-THC on attention and emotional processing. Furthermore, the detrimental effects of cannabis exposure on cognition appear to be driven by $\triangle 9-\mathrm{THC}$, with preparations containing a high $\triangle 9$-THC:CBD ratio causing greater impairments in emotional processing and memory function compared to preparations with low $\triangle 9$-THC:CBD ratio. Limited evidence also suggests potential beneficial effects of CBD alone on emotional processing and some protective effects of $\mathrm{CBD}$ against $\triangle 9$-THC-induced impairments in emotional processing and memory function. Moreover, $\triangle 9-\mathrm{THC}$ and CBD appear to have antagonistic effects on neural networks underlying several cognitive processes, some of which correlate with the harmful (e.g., $\triangle 9$-THC-induced psychotic or anxiety symptoms) or beneficial (e.g., anxiolytic effect of CBD) effects of these cannabinoids on behavior.

\section{Compliance with Ethical Standards}

Conflict of Interest Dr. Marco Colizzi and Dr. Sagnik Bhattacharyya declare that they have no conflict of interest.

Human and Animal Rights and Informed Consent This article does not contain any studies with human or animal subjects performed by any of the authors.

Open Access This article is distributed under the terms of the Creative Commons Attribution 4.0 International License (http:// creativecommons.org/licenses/by/4.0/), which permits unrestricted use, 
distribution, and reproduction in any medium, provided you give appropriate credit to the original author(s) and the source, provide a link to the Creative Commons license, and indicate if changes were made.

\section{References}

Papers of particular interest, published recently, have been highlighted as:

•- Of major importance

1. United Nations Office on Drugs and Crime. World drug report 2016. United Nations publication. Sales No. E.16.XI.7.

2. Moore TH, Zammit S, Lingford-Hughes A, Barnes TR, Jones PB, Burke $\mathrm{M}$, et al. Cannabis use and risk of psychotic or affective mental health outcomes: a systematic review. Lancet. 2007;370(9584):319-28.

3. Murray RM, Morrison PD, Henquet C, Di Forti M. Cannabis, the mind and society: the hash realities. Nat Rev Neurosci. 2007;8(11): 885-95.

4. Schoeler T, Petros N, Di Forti M, Pingault JB, Klamerus E, Foglia E, et al. Association between continued cannabis use and risk of relapse in first-episode psychosis: a quasi-experimental investigation within an observational study. JAMA Psychiatry. 2016;73(11):1173-9.

5. Schoeler T, Petros N, Di Forti M, Klamerus E, Foglia E, Ajnakina $\mathrm{O}$, et al. Effects of continuation, frequency, and type of cannabis use on relapse in the first 2 years after onset of psychosis: an observational study. Lancet Psychiatry. 2016;3(10):947-53.

6. Schoeler T, Monk A, Sami MB, Klamerus E, Foglia E, Brown R, et al. Continued versus discontinued cannabis use in patients with psychosis: a systematic review and meta-analysis. Lancet Psychiatry. 2016;3(3):215-25.

7. Patel R, Wilson R, Jackson R, Ball M, Shetty H, Broadbent M, et al. Association of cannabis use with hospital admission and antipsychotic treatment failure in first episode psychosis: an observational study. BMJ Open. 2016;6(3):e009888.

8. Colizzi M, Carra E, Fraietta S, Lally J, Quattrone D, Bonaccorso S, et al. Substance use, medication adherence and outcome one year following a first episode of psychosis. Schizophr Res. 2016;170(23):311-7.

9. D'Souza DC, Perry E, MacDougall L, Ammerman Y, Cooper T, Wu YT, et al. The psychotomimetic effects of intravenous delta-9tetrahydrocannabinol in healthy individuals: implications for psychosis. Neuropsychopharmacology. 2004;29(8):1558-72.

10. Bhattacharyya S, Atakan Z, Martin-Santos R, Crippa JA, Kambeitz J, Prata D, et al. Preliminary report of biological basis of sensitivity to the effects of cannabis on psychosis: AKT1 and DAT1 genotype modulates the effects of delta-9-tetrahydrocannabinol on midbrain and striatal function. Mol Psychiatry. 2012;17(12):1152-5.

11. Bhattacharyya S, Fusar-Poli P, Borgwardt S, Martin-Santos R, Nosarti C, O'Carroll C, et al. Modulation of mediotemporal and ventrostriatal function in humans by delta9-tetrahydrocannabinol: a neural basis for the effects of Cannabis sativa on learning and psychosis. Arch Gen Psychiatry. 2009;66(4):442-51.

12. Appiah-Kusi E, Leyden E, Parmar S, Mondelli V, McGuire P, Bhattacharyya $\mathrm{S}$. Abnormalities in neuroendocrine stress response in psychosis: the role of endocannabinoids. Psychol Med. 2016;46(1):27-45.

13. Owen M, Sawa A, Mortensen P. Schizophrenia. Lancet. 2016;388(10039):86-97.

14. Bolla KI, Brown K, Eldreth D, Tate K, Cadet JL. Dose-related neurocognitive effects of marijuana use. Neurology. 2002;59(9): 1337-43.
15. Jockers-Scherubl MC, Wolf T, Radzei N, Schlattmann P, Rentzsch J, Gomez-Carrillo de Castro A, et al. Cannabis induces different cognitive changes in schizophrenic patients and in healthy controls. Prog Neuro-Psychopharmacol Biol Psychiatry. 2007;31(5):1054 63.

16. Solowij N, Stephens RS, Roffman RA, Babor T, Kadden R, Miller $\mathrm{M}$, et al. Cognitive functioning of long-term heavy cannabis users seeking treatment. JAMA. 2002;287(9):1123-31.

17. Schoeler T, Kambeitz J, Behlke I, Murray R, Bhattacharyya S. The effects of cannabis on memory function in users with and without a psychotic disorder: findings from a combined meta-analysis. Psychol Med. 2016;46(1):177-88.

18. Pope HG Jr, Gruber AJ, Hudson JI, Huestis MA, Yurgelun-Todd D. Neuropsychological performance in long-term cannabis users. Arch Gen Psychiatry. 2001;58(10):909-15.

19. Mata I, Rodriguez-Sanchez JM, Pelayo-Teran JM, Perez-Iglesias R, Gonzalez-Blanch C, Ramirez-Bonilla M, et al. Cannabis abuse is associated with decision-making impairment among first-episode patients with schizophrenia-spectrum psychosis. Psychol Med. 2008;38(9):1257-66.

20. Schnell T, Koethe D, Daumann J, Gouzoulis-Mayfrank E. The role of cannabis in cognitive functioning of patients with schizophrenia. Psychopharmacology. 2009;205(1):45-52.

21. Sevy S, Burdick KE, Visweswaraiah H, Abdelmessih S, Lukin M, Yechiam E, et al. Iowa gambling task in schizophrenia: a review and new data in patients with schizophrenia and co-occurring cannabis use disorders. Schizophr Res. 2007;92(1-3):74-84.

22. Ruiz-Contreras AE, Carrillo-Sanchez K, Gomez-Lopez N, VadilloOrtega F, Hernandez-Morales S, Carnevale-Cantoni A, et al. Working memory performance in young adults is associated to the AATn polymorphism of the CNR1 gene. Behav Brain Res. 2013;236(1):62-6.

23. Ruiz-Contreras AE, Carrillo-Sanchez K, Ortega-Mora I, BarreraTlapa MA, Roman-Lopez TV, Rosas-Escobar CB, et al. Performance in working memory and attentional control is associated with the rs2180619 SNP in the CNR1 gene. Genes Brain Behav. 2014;13(2):173-8.

24. Colizzi M, Fazio L, Ferranti L, Porcelli A, Masellis R, Marvulli D, et al. Functional genetic variation of the cannabinoid receptor 1 and cannabis use interact on prefrontal connectivity and related working memory behavior. Neuropsychopharmacology. 2015;40(3):640-9.

25. Taurisano P, Antonucci LA, Fazio L, Rampino A, Romano R, Porcelli A, et al. Prefrontal activity during working memory is modulated by the interaction of variation in $\mathrm{CB} 1$ and $\mathrm{COX} 2$ coding genes and correlates with frequency of cannabis use. Cortex. 2016;81:231-8.

26. Bhattacharyya S, Atakan Z, Martin-Santos R, Crippa JA, Kambeitz $\mathrm{J}$, Prata D, et al. Preliminary report of biological basis of sensitivity to the effects of cannabis on psychosis: AKT1 and DAT1 genotype modulates the effects of delta-9-tetrahydrocannabinol on midbrain and striatal function. Mol. Psychiatry. 2012;17:1152-5.

27. van Winkel R, van Beveren NJ, Simons C, Genetic R. Outcome of psychosis I. AKT1 moderation of cannabis-induced cognitive alterations in psychotic disorder. Neuropsychopharmacology. 2011;36(12):2529-37.

28. Colizzi M, Iyegbe C, Powell J, Ursini G, Porcelli A, Bonvino A, et al. Interaction between functional genetic variation of DRD2 and cannabis use on risk of psychosis. Schizophr Bull. 2015;41(5): 1171-82.

29. Bhattacharyya S, Iyegbe C, Atakan Z, Martin-Santos R, Crippa JA, $\mathrm{Xu}$ X, et al. Protein kinase B (AKT1) genotype mediates sensitivity to cannabis-induced impairments in psychomotor control. Psychol Med. 2014;44(15):3315-28.

30. Grant I, Gonzalez R, Carey CL, Natarajan L, Wolfson T. Non-acute (residual) neurocognitive effects of cannabis use: a meta-analytic study. J Int Neuropsychol Soc. 2003;9(5):679-89. 
31. Meier MH, Caspi A, Ambler A, Harrington H, Houts R, Keefe RS, et al. Persistent cannabis users show neuropsychological decline from childhood to midlife. Proc Natl Acad Sci U S A. 2012;109(40):E2657-64.

32. Jager G, Block RI, Luijten M, Ramsey NF. Cannabis use and memory brain function in adolescent boys: a cross-sectional multicenter functional magnetic resonance imaging study. J Am Acad Child Adolesc Psychiatry. 2010;49(6):561-72. 72 e1-3

33. Jager G, Van Hell HH, De Win MM, Kahn RS, Van Den Brink W, Van Ree JM, et al. Effects of frequent cannabis use on hippocampal activity during an associative memory task. Eur Neuropsychopharmacol. 2007;17(4):289-97.

34. Bossong MG, Jager G, van Hell HH, Zuurman L, Jansma JM, Mehta MA, et al. Effects of delta9-tetrahydrocannabinol administration on human encoding and recall memory function: a pharmacological FMRI study. J Cogn Neurosci. 2012;24(3):588-99.

35. Bossong MG, Jager G, Bhattacharyya S, Allen P. Acute and non-acute effects of cannabis on human memory function: a critical review of neuroimaging studies. Curr Pharm Des. 2014;20(13):2114-25.

36. Mechoulam R, Gaoni Y. Recent advances in the chemistry of hashish. Fortschritte der Chemie organischer Naturstoffe Progress in the chemistry of organic natural products. 1967;25:175-213.

37. Mechoulam R, Shani A, Edery H, Grunfeld Y. Chemical basis of hashish activity. Science. 1970;169(3945):611-2.

38. Niesink RJ, van Laar MW. Does cannabidiol protect against adverse psychological effects of THC? Front Psychiatry. 2013;4:130.

39. Radhakrishnan R, Wilkinson ST, D'Souza DC. Gone to pot-a review of the association between cannabis and psychosis. Front Psychiatry. 2014;5:54.

40. Colizzi M, McGuire P, Pertwee RG, Bhattacharyya S. Effect of cannabis on glutamate signalling in the brain: a systematic review of human and animal evidence. Neurosci Biobehav Rev. 2016;64: 359-81.

41. Bhattacharyya S, Atakan Z, Martin-Santos R, Crippa JA, McGuire PK. Neural mechanisms for the cannabinoid modulation of cognition and affect in man: a critical review of neuroimaging studies. Curr Pharm Des. 2012;18(32):5045-54.

42. Di Forti M, Marconi A, Carra E, Fraietta S, Trotta A, Bonomo M, et al. Proportion of patients in south London with first-episode psychosis attributable to use of high potency cannabis: a casecontrol study. Lancet Psychiatry. 2015;2(3):233-8.

43. Zamberletti E, Beggiato S, Steardo L Jr, Prini P, Antonelli T, Ferraro $\mathrm{L}$, et al. Alterations of prefrontal cortex GABAergic transmission in the complex psychotic-like phenotype induced by adolescent delta9-tetrahydrocannabinol exposure in rats. Neurobiol Dis. 2014;63: 35-47.

44. Campolongo P, Trezza V, Cassano T, Gaetani S, Morgese MG, Ubaldi M, et al. Perinatal exposure to delta-9-tetrahydrocannabinol causes enduring cognitive deficits associated with alteration of cortical gene expression and neurotransmission in rats. Addict Biol. 2007;12(3-4):485-95.

45. Ranganathan M, D'Souza DC. The acute effects of cannabinoids on memory in humans: a review. Psychopharmacology. 2006;188(4): 425-44.

46. Hall W, Solowij N. Adverse effects of cannabis. Lancet. 1998;352(9140):1611-6.

47. Curran HV, Brignell C, Fletcher S, Middleton P, Henry J. Cognitive and subjective dose-response effects of acute oral delta 9tetrahydrocannabinol (THC) in infrequent cannabis users. Psychopharmacology. 2002;164(1):61-70.

48. D'Souza DC, Ranganathan M, Braley G, Gueorguieva R, Zimolo Z, Cooper T, et al. Blunted psychotomimetic and amnestic effects of delta-9-tetrahydrocannabinol in frequent users of cannabis. Neuropsychopharmacology. 2008;33(10):2505-16.

49. Batalla A, Crippa JA, Busatto GF, Guimaraes FS, Zuardi AW, Valverde $\mathrm{O}$, et al. Neuroimaging studies of acute effects of THC and CBD in humans and animals: a systematic review. Curr Pharm Des. 2014;20(13):2168-85.

50. Morgan CJ, Gardener C, Schafer G, Swan S, Demarchi C, Freeman TP, et al. Sub-chronic impact of cannabinoids in street cannabis on cognition, psychotic-like symptoms and psychological well-being. Psychol Med. 2012;42(2):391-400.

51. Morgan CJ, Schafer G, Freeman TP, Curran HV. Impact of cannabidiol on the acute memory and psychotomimetic effects of smoked cannabis: naturalistic study: naturalistic study [corrected]. Br J Psychiatry. 2010;197(4):285-90.

52.• Englund A, Morrison PD, Nottage J, Hague D, Kane F, Bonaccorso $\mathrm{S}$, et al. Cannabidiol inhibits THC-elicited paranoid symptoms and hippocampal-dependent memory impairment. J Psychopharmacol. 2013;27(1):19-27. Compared to CBD pretreatment, placebo pretreatment is associated with a poorer verbal memory performance following $\Delta$ 9-THC administration. $\Delta$ 9-THC administration affects working memory performance following pretreatment with placebo, while pretreatment with $\mathrm{CBD}$ is able to partially prevent the detrimental effects of $\Delta 9$-THC on working memory.

53.• Hindocha C, Freeman TP, Schafer G, Gardener C, Das RK, Morgan CJ, et al. Acute effects of delta-9-tetrahydrocannabinol, cannabidiol and their combination on facial emotion recognition: a randomised, double-blind, placebo-controlled study in cannabis users. Eur Neuropsychopharmacol. 2015;25(3):325-34. Administration of $\Delta$ 9-THC alone has a detrimental effect on emotional processing accuracy. This effect is no longer present is $\Delta 9-\mathrm{THC}$ is administered in combination with CBD. Administration of CBD alone is associated with higher emotional processing accuracy compared to placebo.

54. Roser P, Juckel G, Rentzsch J, Nadulski T, Gallinat J, Stadelmann AM. Effects of acute oral delta9-tetrahydrocannabinol and standardized cannabis extract on the auditory P 300 event-related potential in healthy volunteers. Eur Neuropsychopharmacol. 2008;18(8): $569-77$.

55. Schoedel KA, Chen N, Hilliard A, White L, Stott C, Russo E, et al. A randomized, double-blind, placebo-controlled, crossover study to evaluate the subjective abuse potential and cognitive effects of nabiximols oromucosal spray in subjects with a history of recreational cannabis use. Hum Psychopharmacol. 2011;26(3):224-36.

56. Gruber SA, Sagar KA, Dahlgren MK, Racine MT, Smith RT, Lukas SE. Splendor in the grass? A pilot study assessing the impact of medical marijuana on executive function. Front Pharmacol. 2016;7: 355.

57. Wade DT, Robson P, House H, Makela P, Aram J. A preliminary controlled study to determine whether whole-plant cannabis extracts can improve intractable neurogenic symptoms. Clin Rehabil. 2003;17(1):21-9.

58.• Bhattacharyya S, Morrison PD, Fusar-Poli P, Martin-Santos R, Borgwardt S, Winton-Brown T, et al. Opposite effects of delta-9tetrahydrocannabinol and cannabidiol on human brain function and psychopathology. Neuropsychopharmacology. 2010;35(3):764 74. $\triangle$ 9-THC and CBD have opposite effects on neural networks underlying several cognitive processes, including verbal memory, emotional processing, executive function, and visual and auditory processing. Some of these effects correlate with the harmful (e.g., $\Delta$ 9-THC-induced psychotic or anxiety symptoms) or beneficial (e.g., anxiolytic effect of CBD) effects of these cannabinoids on behavior.

59. Winton-Brown TT, Allen P, Bhattacharyya S, Borgwardt SJ, FusarPoli P, Crippa JA, et al. Modulation of auditory and visual processing by delta-9-tetrahydrocannabinol and cannabidiol: an FMRI study. Neuropsychopharmacology. 2011;36(7):1340-8.

60. Bhattacharyya S, Crippa JA, Allen P, Martin-Santos R, Borgwardt $\mathrm{S}$, Fusar-Poli $\mathrm{P}$, et al. Induction of psychosis by delta9tetrahydrocannabinol reflects modulation of prefrontal and striatal 
function during attentional salience processing. Arch Gen Psychiatry. 2012;69(1):27-36.

61.• Bhattacharyya S, Falkenberg I, Martin-Santos R, Atakan Z, Crippa JA, Giampietro V, et al. Cannabinoid modulation of functional connectivity within regions processing attentional salience. Neuropsychopharmacology. 2015;40(6):1343-52. $\mathbf{\Delta 9 - T H C}$ and CBD have opposite effects on functional connectivity between the dorsal striatum, the prefrontal cortex, and the hippocampus. Mediotemporal-prefrontal connectivity is enhanced under the $\triangle 9$-THC condition, but reduced following CBD administration. Fronto-striatal connectivity is enhanced by CBD, but reduced under $\Delta$ 9-THC. Effect of $\Delta$ 9-THC on fronto-striatal connectivity correlates with response latency while performing the task.

62. Englund A, Atakan Z, Kralj A, Tunstall N, Murray R, Morrison P. The effect of five day dosing with THCV on THC-induced cognitive, psychological and physiological effects in healthy male human volunteers: a placebo-controlled, double-blind, crossover pilot trial. J Psychopharmacol. 2016;30(2):140-51.

63. Hallak JE, Machado-de-Sousa JP, Crippa JA, Sanches RF, Trzesniak C, Chaves C, et al. Performance of schizophrenic patients in the Stroop Color Word Test and electrodermal responsiveness after acute administration of cannabidiol (CBD). Rev Bras Psiquiatr. 2010;32(1):56-61.

64. Potter DJ, Clark P, Brown MB. Potency of delta 9-THC and other cannabinoids in cannabis in England in 2005: implications for psychoactivity and pharmacology. J Forensic Sci. 2008;53(1):90-4.

65. ElSohly MA, Mehmedic Z, Foster S, Gon C, Chandra S, Church JC. Changes in cannabis potency over the last 2 decades (19952014): analysis of current data in the United States. Biol Psychiatry. 2016;79(7):613-9.

66. Swift W, Wong A, Li KM, Arnold JC, McGregor IS. Analysis of cannabis seizures in NSW, Australia: cannabis potency and cannabinoid profile. PLoS One. 2013;8(7):e70052.

67. Cascini F, Aiello C, Di Tanna G. Increasing delta-9tetrahydrocannabinol (delta-9-THC) content in herbal cannabis over time: systematic review and meta-analysis. Curr Drug Abuse Rev. 2012;5(1):32-40.

68. Pope HG Jr, Yurgelun-Todd D. The residual cognitive effects of heavy marijuana use in college students. JAMA. 1996;275(7): 521-7.

69. Pope HG Jr. Cannabis, cognition, and residual confounding. JAMA. 2002;287(9):1172-4.

70. Eldreth DA, Matochik JA, Cadet JL, Bolla KI. Abnormal brain activity in prefrontal brain regions in abstinent marijuana users. NeuroImage. 2004;23(3):914-20.
71. Pertwee RG. The diverse CB1 and CB2 receptor pharmacology of three plant cannabinoids: delta9-tetrahydrocannabinol, cannabidiol and delta9-tetrahydrocannabivarin. Br J Pharmacol. 2008;153(2): 199-215.

72. Zuardi AW, Karniol IG. Effects on variable-interval performance in rats of delta 9-tetrahydrocannabinol and cannabidiol, separately and in combination. Braz J Med Biol Res. 1983;16(2):141-6.

73. Musty RE, Sands R. Effects of marijuana extract distillate and cannabidiol on variable interval performance as a function of food deprivation. Pharmacology. 1978;16(4):199-205.

74. Guimaraes FS, Chiaretti TM, Graeff FG, Zuardi AW. Antianxiety effect of cannabidiol in the elevated plus-maze. Psychopharmacology. 1990;100(4):558-9.

75. Onaivi ES, Green MR, Martin BR. Pharmacological characterization of cannabinoids in the elevated plus maze. J Pharmacol Exp Ther. 1990;253(3):1002-9.

76. Guimaraes FS, de Aguiar JC, Mechoulam R, Breuer A. Anxiolytic effect of cannabidiol derivatives in the elevated plus-maze. Gen Pharmacol. 1994;25(1):161-4.

77. Zuardi AW, Cosme RA, Graeff FG, Guimaraes FS. Effects of ipsapirone and cannabidiol on human experimental anxiety. J Psychopharmacol. 1993;7(1 Suppl):82-8.

78. Zuardi AW, Shirakawa I, Finkelfarb E, Karniol IG. Action of cannabidiol on the anxiety and other effects produced by delta 9THC in normal subjects. Psychopharmacology. 1982;76(3):245-50.

79. Crippa JA, Derenusson GN, Ferrari TB, Wichert-Ana L, Duran FL, Martin-Santos R, et al. Neural basis of anxiolytic effects of cannabidiol (CBD) in generalized social anxiety disorder: a preliminary report. J Psychopharmacol. 2011;25(1):121-30.

80. Osborne AL, Solowij N, Weston-Green K. A systematic review of the effect of cannabidiol on cognitive function: relevance to schizophrenia. Neurosci Biobehav Rev. 2016;72:310-24.

81. Colizzi M, Iyegbe C, Powell J, Blasi G, Bertolino A, Murray RM, et al. Interaction between DRD2 and AKT1 genetic variations on risk of psychosis in cannabis users: a case-control study. NPJ Schizophr. 2015;1:15025.

82. Bhattacharyya S, Atakan Z, Martin-Santos R, Crippa JA, Kambeitz $\mathrm{J}$, Malhi S, et al. Impairment of inhibitory control processing related to acute psychotomimetic effects of cannabis. Eur Neuropsychopharmacol. 2015;25(1):26-37.

83. Schoeler T, Theobald D, Pingault JB, Farrington DP, Jennings WG, Piquero AR, et al. Continuity of cannabis use and violent offending over the life course. Psychol Med. 2016;46(8):1663-77.

84. Velayudhan L, Van Diepen E, Marudkar M, Hands O, Suribhatla S, Prettyman R, et al. Therapeutic potential of cannabinoids in neurodegenerative disorders: a selective review. Curr Pharm Des. 2014;20(13):2218-30. 